This item was submitted to Loughborough's Research Repository by the author.

Items in Figshare are protected by copyright, with all rights reserved, unless otherwise indicated.

\title{
Is fiscal fatigue a threat to consolidation programmes?
}

PLEASE CITE THE PUBLISHED VERSION

http://dx.doi.org/10.1177/0263774X15597391

\section{PUBLISHER}

(c) SAGE

VERSION

AM (Accepted Manuscript)

\section{PUBLISHER STATEMENT}

This work is made available according to the conditions of the Creative Commons Attribution-NonCommercialNoDerivatives 4.0 International (CC BY-NC-ND 4.0) licence. Full details of this licence are available at: https://creativecommons.org/licenses/by-nc-nd/4.0/

\section{LICENCE}

CC BY-NC-ND 4.0

\section{REPOSITORY RECORD}

Agnello, Luca, Vitor Castro, and Ricardo M. Sousa. 2019. "Is Fiscal Fatigue a Threat to Consolidation Programmes?". figshare. https://hdl.handle.net/2134/25014. 


\title{
Is fiscal fatigue a threat to consolidation programmes?
}

\author{
Luca Agnello
}

Department of Economics, Business and Statistics (SEAS), University of Palermo, Viale delle Scienze, 90128 Palermo, Italy; E-mail: luca.agnello01@unipa.it

\section{Vítor Castro}

Faculty of Economics, University of Coimbra, Av Dias da Silva, 165, 3004-512 Coimbra, Portugal; Economic Policies Research Unit (NIPE), University of Minho, Campus of Gualtar, 4710-057 Braga, Portugal; E-mail: vcastro@fe.uc.pt

\section{Ricardo M Sousa}

Department of Economics and Economic Policies Research Unit (NIPE),University of Minho, Campus of Gualtar, 4710-057 Braga, Portugal; and LSE Alumni Association, London School of Economics, Houghton Street, London WC2 2AE, United Kingdom; e-mails: rjsousa@eeg.uminho.pt,rjsousa@alumni.lse.ac.uk

\begin{abstract}
Building on a narrative approach to identify episodes of fiscal consolidation, data for a group of seventeen industrial countries over the period 1978-2009, and continuous-time duration models, we find evidence suggesting that the likelihood of a fiscal consolidation ending increases over time, but only for programmes that last fewer than six years. Additionally, fiscal consolidations tend to last longer in non-European than in European countries. Our results emphasize that chronic fiscal imbalances might lead to a vicious austerity cycle, while discipline in the behaviour of fiscal authorities is a means of achieving credible and shorter adjustment measures. Therefore, fiscal fatigue is likely to compromise the implementation and successfulness of fiscal consolidation programmes.
\end{abstract}

Keywords: fiscal consolidation, duration analysis, Weibull model, duration dependence, change points

"The countries in the euro zone shouldn't add any more austerity programs ... . Such measures could lead to a downward spiral and need to be delayed until the economy recovers."

Peter Bofinger (20 July, 2012)

\section{Introduction}

The financial crisis of 2008-2009 demanded a quick and aggressive response by monetary authorities. However, its severity highlighted the need of large fiscal stimulus programmes as additional ingredients of the policy mix. Not surprisingly, fiscal authorities in several developed countries have actively engaged in expansionary fiscal measures and implemented comprehensive expenditure hikes which, together with substantial cyclical revenue losses, have led to a sharp widening of budget deficits. The occurrence of the global financial turmoil has, thus, became key for investigating the macroeconomic effect of fiscal policy (Agnello and Schuknecht, 2011; Agnello and Sousa, 2011; Agnello et al, 2012; Castro, 2010).

More recently, the concerns about long-term (un)sustainability of public finances have given support to the view that such a stimulus needs to be withdrawn and budgetary consolidation measures should be put in place. However, although there seems to be an agreement on the long-term benefits of government debt reductions, there is no unified view on the short-term effects of fiscal austerity. In fact, apart from the uncertainty about the effect that fiscal retrenchments have on economic performance, some authors have started 
to argue that business cycle desynchronization is just one of the most visible consequences of the extraordinary challenges faced by some countries (Mallick and Mohsin, 2007, 2010; Rafiq and Mallick, 2008). In addition, these interventions can negatively impinge on the relationship between monetary and financial stability (Castro, 2011a; Castro and Sousa, 2012; Granville and Mallick, 2009; Sousa, 2010).

In this context, investigating the nature of fiscal consolidations programmes is crucial for a timely formulation of policies that can help to fine-tune the trade-off between consolidation of public finances and economic growth. How long is the consolidation programme likely to last? How similar (or different) are programmes implemented in European countries from those put in place elsewhere? Does the end of a fiscal adjustment depend on its own age? Can we detect the presence of change points in the duration dependence of fiscal consolidations? Can fiscal fatigue undermine the implementation of consolidation programmes?

These are questions that have gained a renewed momentum in recent times, especially if one takes into account that there is considerable disagreement about the timing and the length of the fiscal adjustments that are necessary to close the gap in public finances brought about by the wide range of policies that governments employed in order to deal with the most recent financial crisis. In fact, whereas among countries of the euro area the tone has been concerned about the need of fiscal austerity in a relatively short period of time as a precondition for sustainable growth and a credible path for fiscal stance, other countries such as the US and the UK have emphasized that fiscal consolidation may damage growth in the short run and become counterproductive, and, thus, have allowed for a longer programmes. In this work we aim at providing the answers to the above-mentioned questions and challenges.

We start by building on the narrative approach used for the identification of fiscal consolidation (Devries et al, 2011). Therefore, rather than looking at fiscal outcomes, policy actions aimed at deficit reduction are evaluated by the analysis of accounts and records of what governments were planning to do at the time of publications (such as the IMF Economic Developments Reports and Staff Reports, and the OECD Economic Surveys).

Then, we use data for a group of 17 industrialized countries over the period 1978-2009 to investigate whether the likelihood of a fiscal consolidation ending depends on its own age, ie, whether fiscal consolidation programs are duration dependent. In line with the work of Illera and Mulas-Granados (2002), we use continuous-time duration models and find evidence of positive duration dependence, which implies that the likelihood of fiscal consolidation programmes ending indeed increases over time.

Finally, we assess a dimension that has been typically neglected in this strand of the literature: the existence of breaks in the duration dependence. Though the existing works assume that the behaviour of duration dependence is smooth (ie, either constant or increasing) over time, we conjecture that the degree of likelihood of a fiscal consolidation ending as it gets older may change after a certain duration. To proceed with such task, we extend the baseline Weibull duration model in order to allow for the presence of a change point in the duration dependence parameter.

The results indicate that the positive duration dependence is present in fiscal consolidations that last fewer than six years, but no evidence of duration dependence is found for older consolidations. This represents a remarkable new finding in this field of research and an important contribution to the literature. Indeed, it suggests that countries experiencing fiscal adjustments lasting more than six consecutive years are more likely to become trapped in a vicious cycle of fiscal consolidation. More specifically, in the presence of chronic fiscal imbalances, consolidation measures may become more persistent and, as a result, the time for an exit strategy can be surrounded by high uncertainty. This helps to explain why the probability of consolidation ending declines at a lower pace for programmes that last more 
than six years; thereby, suggesting that fiscal fatigue may threaten the successfulness of consolidation programmes.

Additionally, our findings show that fiscal consolidations tend to last longer in nonEuropean than in European countries. The need to comply with the Stability and Growth Pact rules and, from an historical point of view, the commitment with respect to the Maastricht criteria for entry to the European Monetary Union (EMU) can contribute to describe such feature. In addition, the push towards fast corrections of the budget deficits and the fear of suffering debt-financing crisis on the financial markets have typically led to the launch of discretionary countercyclical fiscal measures. This also helps to justify the occurrence of shorter fiscal consolidation programmes in European countries.

The rest of the paper is organized as follows. In section 2 we review the existing literature on the duration of fiscal consolidation. In section 3 we present the econometric model and the empirical methodology and in section 4 we describe the data and discuss the results. Finally, we conclude the paper in section 5 .

\section{Literature review}

There is a relatively large number of works investigating the effect of fiscal consolidation on growth. In fact, the argument about the effectiveness of fiscal policy can be dated back to the Keynesian model, and the empirical evidence also seems to support the existence of a positive short-term effect of fiscal policy on consumption and output (Blanchard and Perotti, 2002; Mountford and Uhlig, 2009).

Despite this, other studies suggest the possibility that fiscal policy measures might have non-Keynesian effects. ${ }^{(1)}$ Fiscal contractions can be 'expansionary' because of the improvement in household and business confidence, thereby stimulating the economy even in the short term (Feldstein, 1982; Giavazzi and Pagano, 1990). Afonso et al, (2010) highlight the importance of distinguishing between the discretionary component of fiscal policy and the endogenous response of fiscal deficits to output or the strength of the automatic stabilizers. ${ }^{(2)}$

From a theoretical point of view, expansionary effects of fiscal adjustments can work via both the demand and the supply side. On the demand side a fiscal adjustment may be expansionary if it supports the belief that the stabilization is credible and avoids a default on government debt (Blanchard, 1990). As a result, a lower premium on government bonds may be requested and the associated (positive) wealth effect can boost private spending (Alesina and Ardagna, 2010).

Another crucial policy issue is whether cutting spending or raising taxes is more likely to stabilize the fiscal stance and generate economic growth. Alesina and Perotti (1995) suggest that a fiscal consolidation is successful if the reduction in the debt-to-GDP ratio is sufficiently large and persistent. Alesina and Ardagna (2010) show that tax cuts are more expansionary than spending increases. In contrast, spending cuts are much more effective in terms of debt stabilization. Tagkalakis (2011) finds that the successfulness of fiscal consolidation is higher when budgetary and economic conditions are worse. Similarly, Afonso and Jalles (2012)

(1) In this context Castro (2011b) finds that the growth of real GDP per capita in the EU was not negatively affected by the implementation of fiscal rules and, consequently, the implementation of the Stability and Growth Pact was not harmful from a growth perspective. Afonso and Sousa (2012) show that government spending shocks generally have a small effect on GDP and lead to important crowding-out effects. Afonso and Sousa (2011) find that unexpected variation in fiscal policy can substantially increase the variability of housing and stock prices.

${ }^{(2)}$ For an interesting assessment of the relationship between fiscal and political decentralization and government quality, see Kyriacou and Roca-Sagalés (2011). Nath and Purohit (1995) do not find evidence supporting a dampening effect of expenditure reassignment and fiscal decentralization on state and local governments expenditure. Similarly, Sagbas et al, (2005) show that fiscal decentralization does not avoid the growth of the size of the public sector. 
stress that the cyclically adjusted primary balance and the duration of the fiscal consolidation adjustment contribute to its success, but the same does nothold for revenue-based consolidations.

The literature presented so far has typically focused on the effect of fiscal adjustments on aggregate income, on the trade-off between economic growth and income inequality (Mulas-Granados, 2005), or on income inequality (Agnello and Sousa, 2014). ${ }^{(3)}$ However, the sharp increase in deficits and quick debt build-up that have been recently observed in many developed countries are now calling for a return to 'normal' times via putting into place fiscal austerity measures. This brings a new question into the scene: what is the nature (ie, the timing and length) of the fiscal consolidation process?

In this context the duration analysis gains an important relevance. Having flourished in the engineering and medical fields, its use rapidly spread out to other sciences. In economics it started to be employed in labour economics to assess the duration of unemployment spells and business cycles or (Castro, 2010, 2013; Sichel, 1991; Zuehlke, 2003). The Weibull model with proposed change points was also adapted by Castro (2013) to show that positive duration dependence in expansions is no longer present when these are longer than ten years.

Because of its properties, this kind of analysis is also suitable for studying the duration of fiscal consolidation programmes. For instance, using nonparametric and parametric continuous-time duration models and focusing on a set of political variables, Illera and Mulas-Granados (2002) find evidence of positive duration dependence in fiscal consolidation programmes in the European Union. Similarly, Agnello et al, (2013) show that fiscal variables (such as the budget deficit and the level of public debt) and economic factors (such as the degree of openness, the inflation rate, the interest rate, and per capita GDP) are crucial for the fiscal consolidation process. However, while the previous studies assume that the duration dependence parameter remains unchanged over the entire duration of the event, we challenge this perspective by investigating whether the degree of likelihood of a consolidation ending displays a change point.

\section{Econometric Approach}

\subsection{Duration Analysis}

We start by assuming that the duration variable is defined as the number of periods over which a fiscal consolidation programme is being implemented. If $T$ measures the time span between the beginning of the programme and its end, then $t_{1}, t_{2}, \ldots, t_{n}$ will represent the observed duration of the fiscal consolidation. The probability distribution of the duration variable, $T$, can be specified by the cumulative distribution function, $\mathrm{F}(t)=\operatorname{Pr}(T<t)$, and the corresponding density function is $\mathrm{f}(t)=\mathrm{d} F(t) / \mathrm{d} t$. Alternatively, the distribution of $T$ can be characterized by the survivor function, $\mathrm{S}(t)=\operatorname{Pr}(T \geqslant t)=1-\mathrm{F}(t)$, which measures the probability that the duration of a fiscal consolidation programme is larger or equal to $t$.

A particularly useful function for duration analysis is the hazard function, $\mathrm{h}(t)=\mathrm{f}(t) / \mathrm{S}(t)$, which measures the rate at which fiscal consolidation spells will end at time $t$, given that they lasted until that moment. In other words, it measures the probability of exiting from a state in moment $t$ conditional on the length of time in that state. This function helps to characterize the path of duration dependence. For instance: (a) if $\mathrm{dh}(t) / \mathrm{d} t>0$ for $t=t^{*}$, there is positive duration dependence in $t^{*}$; (b) if $\mathrm{dh}(t) / \mathrm{d} t<0$ for $t=t^{*}$, then there is negative duration dependence in $t^{*}$; and (c) if $\mathrm{dh}(t) / \mathrm{d} t=0$ for $t=t^{*}$, there is no duration dependence. Therefore, when the derivative of the hazard function with respect to time is positive, the probability of a fiscal consolidation ending in moment $t$, given that it has reached $t^{*}$, increases with its age. Thus, the longer the fiscal consolidation programme is, the higher the conditional probability of its end will be.

${ }^{(3)}$ Sepulveda and Martinez-Vazquez (2011) show that fiscal decentralization policies increase poverty, but reduce income inequality. 
From the hazard function, we can derive the integrated hazard function,

$$
\mathrm{H}(t)=\int_{0}^{\mathrm{t}} \mathrm{h}(u) \mathrm{d} u
$$

and compute the survivor function, $\mathrm{S}(t)=\exp [\mathrm{H}(t)]$. Though different parametric continuoustime duration models can measure the magnitude of duration dependence and the impact of other time-invariant variables on the likelihood of an event ending, the most commonly used functional form of the hazard function is the proportional hazard model:

$$
\mathrm{h}(t, x)=\mathrm{h}_{0}(t) \exp (\boldsymbol{x} \boldsymbol{\beta})
$$

where $\mathrm{h}_{0}(t)$ is the baseline hazard function that captures the data dependence of duration and represents an unknown parameter to be estimated; $\boldsymbol{\beta}$ is a $(k \times 1)$ vector of parameters that need to be estimated; and $\boldsymbol{x}$ is a vector of covariates. The proportional hazard model can be estimated without imposing any specific functional form to the baseline hazard function (the so-called 'Cox model'). Given the inappropriateness of this procedure (in particular for studying duration dependence), a popular alternative imposes a specific parametric form for the function $\mathrm{h}_{0}(t)$; that is, the 'Weibull model'.

\subsection{The basic Weibull model}

The Weibull model is characterized by the following (baseline) hazard function:

$$
\mathrm{h}_{0}(t)=\gamma p t^{p-1}
$$

where $p$ parameterizes the duration dependence, $t$ denotes time, $\gamma$ is a constant; moreover, $p>0$ and $\gamma>0$. If $p>1$, the conditional probability of a turning point occurring increases as the phase gets older - that is, there is positive duration dependence; if $p<1$ there is negative duration dependence; and finally, there is no duration dependence if $p=1$. Therefore, by estimating $p$, we can test for duration dependence in fiscal consolidation programmes.

Inserting the Weibull specification for the baseline hazard function, as expressed by equation (2), in the proportional hazard function denoted by equation (1), we get:

$$
\mathrm{h}(t, x)=\gamma p t^{p-1} \exp (\boldsymbol{x} \boldsymbol{\beta}) .
$$

Hence, the corresponding survivor function can be written as:

$$
\mathrm{S}(t, \boldsymbol{x})=\exp \left[-\gamma t^{p} \exp (\boldsymbol{x} \boldsymbol{\beta})\right] \text {. }
$$

This model can be estimated by maximum likelihood, and the log-likelihood function, for a sample of $i=1, \ldots, n$ fiscal consolidations, is given by:

$$
\begin{aligned}
\ln L(\cdot) & =\sum_{i=1}^{n}\left[c_{i} \ln \mathrm{h}\left(t_{i} \boldsymbol{x}_{i}\right)+\ln \mathrm{S}(t, \boldsymbol{x})\right] \\
& =\sum_{i=1}^{n}\left[c_{i}\left[\ln \gamma+\ln p+(p-1) \ln t_{i}+\boldsymbol{x} \boldsymbol{\beta}\right]-\gamma t_{i}^{p} \exp \left(\boldsymbol{x}_{i} \boldsymbol{\beta}\right)\right],
\end{aligned}
$$

where $c_{i}$ indicates when observations are censored. If the sample period under analysis ends before the turning point has been observed, then observations will be censored (ie, $c_{i}=0$ ); when the turning points are observed in the sample period, the observations are not censored (in which case, $c_{i}=1$ ).

\subsection{A Weibull model with change points}

Though the basic structure of the log-likelihood function for the Weibull model allows us to analyze the presence of duration dependence in fiscal consolidations, we also move a step further in that we assess the extent to which the likelihood of a fiscal consolidation ending as 
it gets older changes after a certain duration. Thus, we allow for the possibility of a structural break in the Weibull model and conjecture that the parameters of the baseline hazard function ( $p$ and $\gamma$ ) can change at a certain point (ie, the 'change point') in time. In particular, we expect that the degree of duration dependence, $p$, changes after the event has lasted more than a certain time. Consequently, we do not expect only that the likelihood of a consolidation programme ending increases over time, but also that if it has lasted more than a certain time, the likelihood of ending may change significantly after that point.

We propose a Weibull model for fiscal consolidation with change points that follows the general model framework developed by Castro (2013) for cases where the Weibull distribution, or the respective parameters characterizing the baseline hazard function, vary over time for different intervals, but remain constant within each interval. ${ }^{(4)}$ For simplicity, let us rewrite equation (2) as:

$$
\mathrm{h}_{0}(t)=\gamma p t^{p^{-1}}=\lambda p(\lambda t)^{p-1},
$$

where $\gamma=\lambda^{p}$. Hence, the survival function becomes:

$$
\mathrm{S}(t, \boldsymbol{x})=\exp [-\mathrm{H}(t, \boldsymbol{x})]=\exp \left[-(\lambda t)^{p} \exp (\boldsymbol{x} \boldsymbol{\beta})\right] .
$$

Denoting $\mathrm{g}(t)=\ln \mathrm{H}(t)$ and considering a change point, $\tau_{\mathrm{c}}$, and two intervals, $t_{0}<t \leqslant \tau_{c}$ and $\tau_{c}<t \leqslant t_{T}, \mathrm{~g}(t)$ can be expressed as:

$$
\mathrm{g}(t)=\ln \left(\lambda_{j} t\right)^{p_{j}}
$$

with $j=1$ or $j=2$. Because the continuity of $\mathrm{g}(t)$ in the change point, $\tau_{\mathrm{c}}$, has to be verified, we must impose that:

$$
\ln \left(\lambda_{1} \tau_{\mathrm{c}}\right)^{p_{1}}=\ln \left(\lambda_{2} \tau_{\mathrm{c}}\right)^{p_{2}} .
$$

Solving this equation with respect to $p_{2}$, we get:

$$
p_{2}=p_{1} \frac{\ln \left(\lambda_{1} \tau_{c}\right)}{\ln \left(\lambda_{2} \tau_{c}\right)} \text {. }
$$

Consequently, in the case of the survival time ending in the first interval, we have:

$$
\mathrm{g}(t)_{j=1}=p_{1} \ln \left(\lambda_{1} t\right),
$$

and, similarly, for the survival time ending in the second interval:

$$
\mathrm{g}(t)_{j=2}=p_{2} \ln \left(\lambda_{2} t\right)=p_{1} \frac{\ln \left(\lambda_{1} \tau_{\mathrm{c}}\right)}{\ln \left(\lambda_{2} \tau_{\mathrm{c}}\right)} \ln \left(\lambda_{2} t\right) .
$$

Considering the $i$ th spell (or individual), we get:

$$
\mathrm{g}(t)=d_{1} p 1 \ln \left(\lambda_{1} t_{i}\right)+\left(1-d_{1}\right) p_{1} \frac{\ln \left(\lambda_{1} \tau_{\mathrm{c}}\right)}{\ln \left(\lambda_{2} \tau_{\mathrm{c}}\right)} \ln \left(\lambda_{2} t_{1}\right),
$$

where $d_{i}=1$ if $j=1$ or, more precisely, $t_{0}<t \leqslant \tau_{c}, d_{i}=0$ if $j=2$ - that is, $\tau_{c}<t \leqslant t_{T}$, and $i=1,2, \ldots, n$; that is, the number of spells.

Since $\mathrm{H}\left(t_{i}, \boldsymbol{x}_{i}\right)=\exp \left[\mathrm{g}\left(t_{i}\right)+\boldsymbol{x}_{i} \boldsymbol{\beta}\right]$, the hazard function is, therefore, given by:

$$
\begin{aligned}
\mathrm{h}\left(t_{i}, \boldsymbol{x}_{i}\right) & =\mathrm{dH}\left(t_{i}, \boldsymbol{x}_{i}\right) / \mathrm{d} t_{i}=\mathrm{g}^{\prime}\left(t_{i}\right) \mathrm{H}\left(t_{i}, \boldsymbol{x}_{i}\right) \\
& =d_{i} \frac{p_{1}}{t_{i}}+\left(1-d_{i}\right) \frac{p_{i}}{t_{i}} \frac{\ln \left(\lambda_{1} \tau_{\mathrm{c}}\right)}{\ln \left(\lambda_{2} \tau_{\mathrm{c}}\right)} \mathrm{H}\left(t_{i}, \boldsymbol{x}_{i}\right) .
\end{aligned}
$$

${ }^{(4)}$ For this reason, we are not able to include (time-varying) economic, political, and institutional factors as potential determinants of the duration of fiscal consolidation. 
Attending to the relation between the survivor function and the integrated hazard, $\mathrm{S}\left(t_{i}, \boldsymbol{x}_{i}\right)=\exp \left[-\mathrm{H}\left(t_{i}, \boldsymbol{x}_{i}\right)\right]$, the log-likelihood function can be written as:

$$
\ln L(\cdot)=\sum_{i=1}^{n}\left\{c_{i}\left[\operatorname{lng} g^{\prime}(t)+\mathrm{g}\left(t_{i}\right)+\boldsymbol{x}_{i} \boldsymbol{\beta}\right]-\exp \left[\mathrm{g}\left(t_{i}\right)+\boldsymbol{x}_{i} \boldsymbol{\beta}\right]\right\},
$$

where

$$
\mathrm{g}^{\prime}(t)=d_{i} \frac{p_{1}}{t_{1}}+\left(1-d_{i}\right) \frac{p_{1}}{t_{i}} \frac{\ln \left(\lambda_{1} t_{\mathrm{c}}\right)}{\ln \left(\lambda_{2} t_{\mathrm{c}}\right)} .
$$

This model is estimated by maximum likelihood, given a particular change point $\tau_{\mathrm{c}}$. The relevance of the change point is evaluated by testing whether there is a statistically significant difference between $p_{1}$ and $p_{2}$, that is, whether the duration dependence parameter changes significantly between the two subperiods.

\section{Data and empirical results}

\subsection{Data}

We use annual data for seventeen industrialized countries over the period 1978-2009. ${ }^{(5)}$ Because of the potential correlation between the measurement error of the cyclically adjusted primary budget balance (CAPB) and the economic developments, and the omission of periods during which fiscal consolidation is followed by negative economic news and counterbalancing discretionary stimulus, we rely on the work of Devries et al (2011) and use a narrative approach to identify fiscal consolidation episodes, instead of the standard statistical approach. ${ }^{(6)}$

Therefore, various accounts and records of what policy makers believed at the time that decisions were taken, as well of the budgetary impact of such measures recorded in the year in which they come into effect with the sole goal of reducing the budget deficit to achieve long-term sustainability, are examined. Similarly, only measures that are announced and implemented are considered, temporary and permanent measures are distinguished, and the size and the composition of the fiscal consolidation programme are also quantified. All in all, the narrative approach allows us to eliminate the endogenous response of fiscal policy to short-term output developments.

By organizing the data in spells-where a spell represents the number of years that a fiscal consolidation lasts and is denoted by DurCons - we are able to identify thirty-nine consolidation spells. While testing for the presence of duration dependence in fiscal consolidation and change points in its behaviour, we also allow for differences between European and nonEuropean countries. That is, we test whether there is a significant difference in the average duration of fiscal consolidation, as well as in the duration dependence parameter, $p$, between these two groups of countries. This is done by including the dummy D_EC in the model, which takes the value of one for European countries and 0 otherwise. Additionally, we estimate separate regressions for each of the groups.

We also take into account the effects of some regressors that are assumed to be timeinvariant. For the analysis of the business cycle, Zellner (1990) and Sichel (1991) suggest that the duration of the previous business cycle phases may affect the length of the current phase.

(5) The choice of the countries is dictated by data availability, and our samples includes: Australia, Austria, Belgium, Canada, Denmark, Finland, France, Germany, Ireland, Italy, Japan, Netherlands, Portugal, Spain, Sweden, the United Kingdom, and the United States.

(6) Additionally, the statistical approach includes some degree of arbitrariness due to the assumptions made about the 'amplitude' and the 'duration' of the adjustment in the CAPB. Indeed, changing such thresholds implies a different number of austerity episodes, thereby leading to an inaccurate measure of discretionary fiscal policy. 
Therefore, we test whether that might also be the case for fiscal consolidation, by including the variable DurPrev in the estimations.

In addition, we analyze whether the duration of fiscal consolidation becomes gradually longer or shorter over time, by considering a kind of a trend variable, labelled as Event, which reports the order or observation number of each event over time and for every single country. This variable is equals to 1 for the first event, 2 for the second, and so on. If the coefficient on this variable is significantly smaller (larger) than zero, phase durations get longer (shorter) over time.

In table 1 we report some descriptive statistics for the duration of fiscal consolidation programmes. The table shows the number of spells of fiscal consolidations (Obs), for all countries (All), for European countries (EC) and non-European countries (NEC). Interestingly, fiscal consolidations seem to last longer for non-European countries than for European countries. Whether this difference is statistically significant or not is an issue that we will try to answer with the estimation of the continuous-time Weibull model.

Table 1. Descriptive statistics.

\begin{tabular}{llllll}
\hline Variable & Observations & Mean & SD & Min & Max \\
\hline DurCons & & & & & \\
All & 39 & 4.74 & 3.31 & 1 & 14 \\
EC & 31 & 4.23 & 2.75 & 1 & 10 \\
NEC & 8 & 6.75 & 4.62 & 2 & 14 \\
D_EC & 39 & 0.79 & 0.41 & 0 & 1 \\
Event & 39 & 1.77 & 0.81 & 1 & 4 \\
DurPrev & 22 & 4.05 & 2.59 & 1 & 10
\end{tabular}

Notes. Fiscal consolidation programmes are identified using the work of Devries et al (2011). The table reports the number of episodes (observations), the mean duration (mean), the standard deviation (SD), the minimum (min) and the maximum (max) duration for each spell. The data are annual and comprise seventeen industrialized countries over the period 1978-2009.

\subsection{The baseline model}

The empirical evidence that emerges from the estimation of the Weibull model presented in subsection 3.2. is summarized in table 2. We recall that the estimate of $p$ measures the magnitude of the duration dependence and $\gamma$ corresponds to the estimate of the constant term.

A one-sided test is used to detect the presence of positive duration dependence (ie, whether $p>1$ ) and the sign + indicates significance at a $5 \%$ level. The results provide strong evidence of positive duration dependence for fiscal consolidations, that is, the likelihood of a fiscal consolidation ending increases as the programme becomes older. Moreover, $p$ is statistically lower than or equal to 2 , that is, the statistical analysis of the second-order derivative of the baseline hazard function indicates the presence of decreasing or constant positive duration dependence. Putting it differently, the probability of a fiscal consolidation ending at time $t$, given that it lasted until that period, increases over time, but at a decreasing or constant rate.

In column 1 we assume that the population of individual spells is homogeneous: that is, each fiscal consolidation is under the same risk of ending. Given that this may not be a good description, column 2 allows for the presence of unobserved heterogeneity or frailty. In statistical terms a frailty model is similar to a random-effects model for duration analysis: it represents an unobserved random proportionality factor that modifies the hazard function of an individual spell and accounts for heterogeneity caused by unmeasured covariates or 
Table 2. Duration dependence-basic Weibull model estimation.

\begin{tabular}{|c|c|c|c|c|c|c|c|c|c|}
\hline & (1) & (2) & (3) & (4) & (5) & (6) & (7) & (8) & (9) \\
\hline$\gamma$ & $\begin{array}{l}0.0821 * * * \\
{[0.0258]}\end{array}$ & $\begin{array}{l}0.0793 * * * \\
{[0.0252]}\end{array}$ & $\begin{array}{c}0.0062 \\
{[0.0042]}\end{array}$ & $\begin{array}{c}0.0394 * * \\
{[0.0181]}\end{array}$ & $\begin{array}{c}0.0291 \\
{[0.0183]}\end{array}$ & $\begin{array}{c}0.0044 \\
{[0.0053]}\end{array}$ & $\begin{array}{l}0.0724 * * * \\
{[0.0247]}\end{array}$ & $\begin{array}{l}0.0864 * * * \\
{[0.0321]}\end{array}$ & $\begin{array}{c}0.0324 * \\
{[0.0187]}\end{array}$ \\
\hline$p$ & $\begin{array}{c}1.5038+,{ }^{\mathrm{d}} \\
{[0.1425]}\end{array}$ & $\begin{array}{l}1.5453^{+, \mathrm{d}} \\
{[0.1733]}\end{array}$ & $\begin{array}{l}2.1614^{+, c} \\
{[0.2632]}\end{array}$ & $\begin{array}{l}1.6029^{+, \mathrm{d}} \\
{[0.1178]}\end{array}$ & $\begin{array}{l}1.6144^{+, \mathrm{d}} \\
{[0.1177]}\end{array}$ & $\begin{array}{c}1.7478^{+, c} \\
{[0.2394]}\end{array}$ & $\begin{array}{l}1.3757^{+, \mathrm{d}} \\
{[0.1788]}\end{array}$ & $\begin{array}{l}1.5793^{+, \mathrm{d}} \\
{[0.1440]}\end{array}$ & $\begin{array}{l}1.3884^{+, d} \\
{[0.1306]}\end{array}$ \\
\hline$\Delta p$ & & & & & & & $\begin{array}{c}0.2859^{* *} \\
{[0.1400]}\end{array}$ & & \\
\hline$\theta$ & & $\begin{array}{c}0.0467 \\
{[0.1523]}\end{array}$ & & & & & & & \\
\hline D_EC & & & & $\begin{array}{c}0.7421 * * \\
{[0.3783]}\end{array}$ & $\begin{array}{c}0.7200 * * \\
{[0.3700]}\end{array}$ & $\begin{array}{c}0.6811 \\
{[0.5272]}\end{array}$ & & & \\
\hline Event & & & & & $\begin{array}{c}0.1720 \\
{[0.2565]}\end{array}$ & $\begin{array}{c}0.2079 \\
{[0.3085]}\end{array}$ & & & \\
\hline DurPrev & & & & & & $\begin{array}{r}0.0262 \\
{[0.640]}\end{array}$ & & & \\
\hline $\begin{array}{l}\text { Log- } \\
\text { likelihood }\end{array}$ & -45.06 & -45.05 & -34.15 & -43.2 & -42.94 & -23.07 & -93.78 & -35.15 & -8.03 \\
\hline LR test & & 0.759 & 0.149 & & & & & & \\
\hline SBIC & 97.46 & 101.1 & 71.97 & 97.39 & 100.54 & 61.60 & 198.56 & 77.16 & 20.22 \\
\hline Spells & 39 & 39 & 39 & 39 & 39 & 22 & 39 & 31 & 8 \\
\hline
\end{tabular}

$* * *$ statistically significat at $1 \%$; ** statistically sign ificant at $5 \%$; * statistically significant at $10 \%$.

Notes. Heteroscedasticity and serial autocorrelation robust standard errors clustered by country are reported in square brackets; ${ }^{+}$indicates that $p$ is significantly higher than 1 using a one-sided test with a $5 \%$ significance level; ${ }^{\mathrm{d}}$, and ${ }^{\mathrm{c}}$, indicate decreasing and constant positive duration dependence, respectively; $\Delta p$ is the estimated difference in the duration dependence parameter between European and Non-European countries. In Column 2, the $p$-value of the likelihood ratio (LR) test for unobserved heterogeneity/frailty gives assesses if the estimated variance $(\Theta)$ is different from zero. In Column 3 , the p-value of the LR test analyses the statistical significance of country-specific dummy variables (pooling test), that is, $L R=-2\left(\log L_{r}-\log L_{u}\right)$, where $\mathrm{r}$ and $\mathrm{u}$ correspond to the restricted and unrestricted models, respectively. The Schwartz Bayesian Information Criterion (SBIC) is computed as follows: $\mathrm{SBIC}=2(-\log \mathrm{L}+(\mathrm{k} / 2) \log \mathrm{N})$, where $\mathrm{k}$ is the number of regressors and $\mathrm{N}$ is the number of observations (spells).

measurement errors. In order to include frailty in the Weibull model, the hazard function expressed by equation (3) is modified as follows:

$$
\mathrm{h}(t, \boldsymbol{x} \mid v)=v \mathrm{~h}(t, \boldsymbol{x}),
$$

where $v$ is an unobserved individual-spell effect that scales the no-frailty component. The random variable $v$ is assumed to be positive with unity mean, finite variance $(\theta)$, and independently distributed from $t$ and $x$. The survival function becomes:

$$
\mathrm{S}(t, \boldsymbol{x} \mid v)=[\mathrm{S}(t, \boldsymbol{x})]^{v} .
$$

Because the values of $v$ are not observed, we cannot estimate them. Therefore, we follow Lancaster (1990) and assume $v$ follows a gamma distribution with unity mean and variance $\theta$. Consequently, the frailty survival function can be written as:

$$
\mathrm{S}(t, \boldsymbol{x} \mid \boldsymbol{\beta}, \theta)=[1-\theta \ln \mathrm{S}(t, \boldsymbol{x})]^{-(1 / \theta)} ;
$$

the frailty hazard function becomes:

$$
\mathrm{h}(t, \mathrm{x} \mid \boldsymbol{\beta}, \theta)=\mathrm{h}(t, \boldsymbol{x})[\mathrm{S}(t, \boldsymbol{x} \mid \boldsymbol{\beta}, \theta)]^{\theta} ;
$$


and the corresponding log-likelihood function can be expressed as:

$$
\ln L(\cdot)=\sum_{i=1}^{n}\left\{c_{1}\left[\ln \gamma+\ln p+(p-1) \ln t_{i}+\boldsymbol{\beta}^{\prime} \boldsymbol{x}_{i}\right]-\left(c_{i}+\frac{1}{\theta}\right) \ln \left[1+\gamma t_{i}^{p} \exp \left(\boldsymbol{\beta}^{\prime} \boldsymbol{x}_{i}\right)\right]\right\} .
$$

The variance parameter $(\theta)$, which measures the presence (or absence) of unobserved heterogeneity, is an additional parameter that needs to be estimated. As $\theta$ is always greater than zero, the limiting distribution of the maximum-likelihood estimate of $\theta$ is a normal distribution that is halved or chopped off at the zero bound. Therefore, the likelihood ratio (LR) test used to detect its presence is a 'boundary' test that takes in account the fact that the null distribution is not the usual $\chi^{2}$ with one degree of freedom, but rather a mixture of a $\chi^{2}$ with no degrees of freedom and a $\chi^{2}$ with one degree of freedom The results do not show evidence of unobserved heterogeneity, as corroborated by the $p$-value of the LR test reported at the bottom of column 2 .

Even though the presence of frailty (or 'random effects') has not been detected, individualcountry effects may still be present, given that the sample consists of seventeen countries that may have individual-specific characteristics. Therefore, in column 3 we add country dummy variables to the set of regressors. In this case we test for pooling - that is, the LR test is used to assess whether the model controlling for country-specific effects is preferred to simple pooling. Once again, the $p$-value of the LR test reported at the bottom of Column 3 does not support the existence of country-specific effects.

In column 4 we add the dummy variable D_EC to the set of regressors in order to analyze if the mean duration of fiscal consolidation is statistically different between European and nonEuropean countries. As can be seen, the coefficient associated with D_EC is highly significant and its sign is positive in magnitude, which suggests that fiscal consolidation programmes last longer in Non-European countries. This finding can be related to the traditionally more disciplined fiscal stance of European countries, as a result of the adoption and implementation over time of a set of rules constraining the behaviour of fiscal authorities. For instance, this was the case of the Maastricht criteria for entry in the EMU and the Stability and Growth Pact rules.

In column 5 we control for the possibility that duration of fiscal consolidation is affected over time and, as a result, we include the trend variable (Event) in the model. Although the difference in duration between European and non-European countries remains significant, the findings do not uncover a change in the duration of fiscal consolidations over time.

Additionally, in column 6 we analyze whether the duration of the previous phase (DurPrev) affects the length of the current phase, but no evidence was found in that direction. This experiment implies a substantial reduction in the number of spells, which helps explaining the lack of statistical significance of the coefficient associated with D_EC.

The results presented so far show that the average duration of fiscal consolidation in European countries is significantly different from the one implemented in Non-European countries. However, one question remains: is this explained by the difference in the magnitude of the duration dependence parameter?

To answer the question, in column 7 we replace the parameter $p$ by $p+\Delta p$ DEC, and directly estimate that difference (ie, $\Delta p$ ). The empirical findings confirm that the duration dependence parameter is higher for European countries. As the estimated coefficient, $\Delta p$, is positive and statistically significant, the likelihood of a fiscal consolidation ending increases at a higher rate for these set of countries. Additionally, the estimated duration dependence parameter for the European countries is $1.6616(=1.3757+0.2859)$ with a standard error equal to 0.1332 , which means that evidence of decreasing positive duration dependence also characterizes consolidation processes. 
Finally, in columns 8 and 9 we estimate separate regressions for European countries and non-European countries, respectively. The results confirm that the duration dependence parameter is larger for European countries (1.5793) than for Non-European countries (1.3884).

\subsection{The model with change-points in duration dependence}

The results presented in table 2 rely on the assumption that the magnitude of duration dependence is time-invariant. In figure 1, we plot the survivor functions for all countries and for European versus Non-European countries. It can be seen that the probability (or proportion) of a fiscal consolidation surviving after duration $t_{i}$ substantially decreases as the programme becomes older. The sharp decline is consistent with the existence of positive duration dependence. Moreover, for all countries and Non-European countries, the survivor functions quick fall until $t_{i}=6$ and then evolve at a slower pace. This highlights the possibility of a break in duration dependence and the need of a more flexible framework allowing for a change point in the Weibull distribution at $\tau_{\mathrm{c}}=6$. In fact, figure 1 suggests that the magnitude of duration dependence might be lower when fiscal consolidations are longer than six years
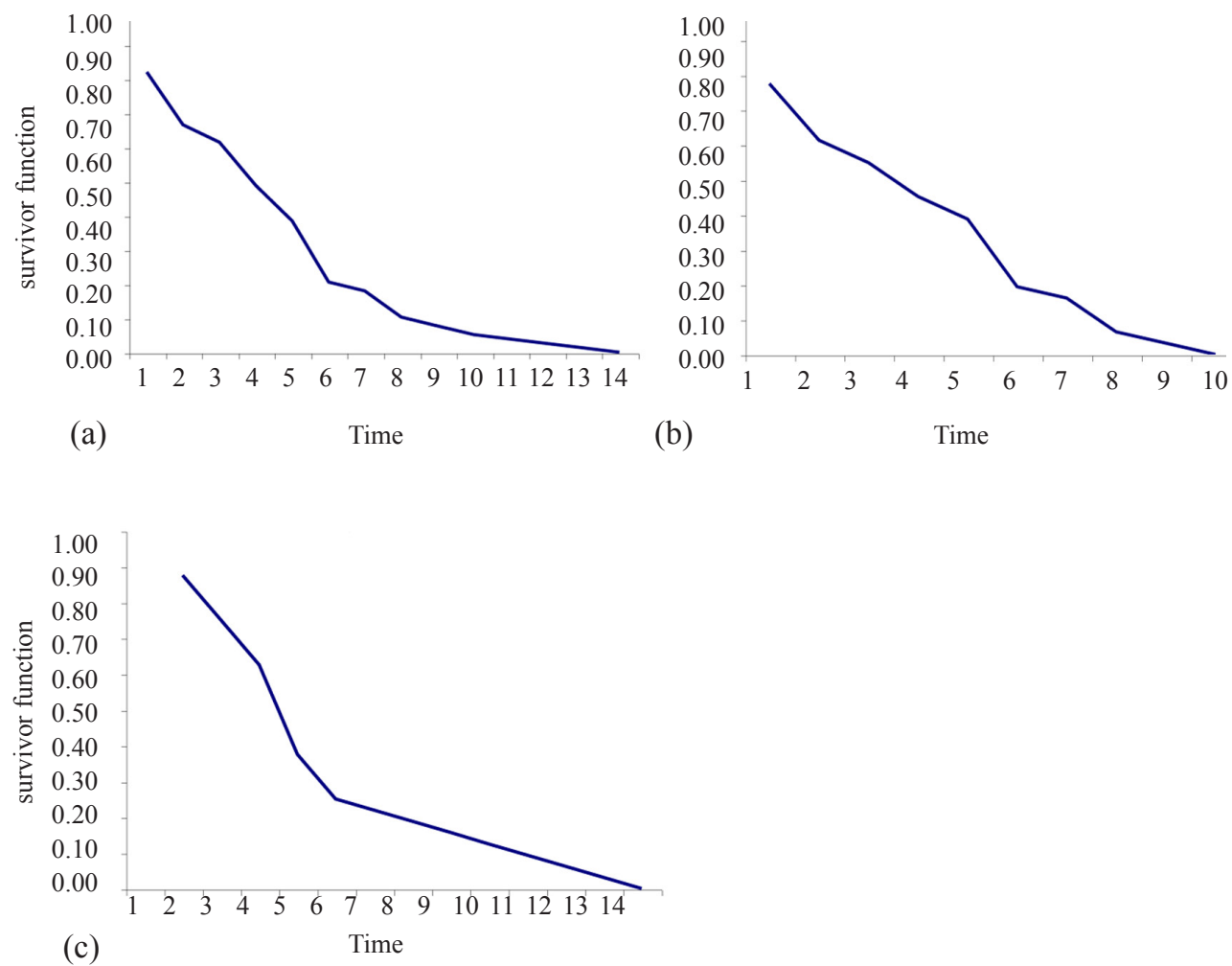

Figure 1. Survivor functions. (a) All countries, (b) European countries, (c) non-European countries.

and the likelihood of a fiscal consolidation ending can significantly change above that period.

Another signal of the existence of a break point in duration dependence is provided by the slope of the survivor functions. In the case of the full sample, the average slope is equal to -0.123 for fiscal consolidations that are shorter than six years and -0.026 for programmes that last longer than six years. Putting it differently, when fiscal consolidations have a duration shorter than six years, each additional year of the program increases the likelihood of its ending by 12.3 percentage points, on average. In contrast, when fiscal consolidations have a length longer than six years, each additional year of the programme rises the likelihood of its ending by 2.6 percentage points. Similar results can be found for the sample of European and Non-European countries: (a) in the case of European countries the difference remains 
substantial, but it is smaller given that the average slope of the survivor function decreases from only -0.116 (in the case of fiscal consolidations that last fewer than six years) to -0.048 (for programmes that have a duration longer than six years); (b) in the case of non-European countries the difference is considerably larger, concerning that the average slope of the survivor function is -0.156 and -0.031 for fiscal consolidations that are shorter and longer than six years, respectively.

In order to test for the presence of differences in the duration dependence parameter, we consider a Weibull model with a change point. Therefore, we estimate two dependence duration parameters, one for the first period $\left(p_{1}\right)$ and another one for the second period $\left(p_{2}\right)$,

Table 3. Duration dependence; Weibull model estimation with change points.

\begin{tabular}{lcccccc}
\hline & $(1)$ & $(2)$ & $(3)$ & $(4)$ & $(5)$ & $(6)$ \\
\hline$\gamma_{1}$ & $0.1998^{* * *}$ & $0.2279^{* * *}$ & $0.2168^{* * *}$ & $0.1965^{*}$ & $0.2079^{* * *}$ & $0.1762^{* * *}$ \\
& {$[0.0183]$} & {$[0.0569]$} & {$[0.0772]$} & {$[0.1029]$} & {$[0.0242]$} & {$[0.0267]$} \\
$\gamma_{2}$ & $0.2158^{* * *}$ & $0.2428^{* * *}$ & $0.2281^{* *}$ & 0.2019 & $0.2010^{* * *}$ & 0.2095 \\
& {$[0.0319]$} & {$[0.0910]$} & {$[0.1089]$} & {$[0.1327]$} & {$[0.0243]$} & {$[0.1532]$} \\
$p_{1}$ & $1.6894^{+, \mathrm{c}}$ & $1.6884^{+, \mathrm{c}}$ & $1.6966^{+, \mathrm{c}}$ & $1.8145^{+, \mathrm{c}}$ & $1.5217^{+, \mathrm{d}}$ & $3.4083^{+, \mathrm{i}}$ \\
& {$[0.2205]$} & {$[0.2130]$} & {$[0.2076]$} & {$[0.2945]$} & {$[0.1758]$} & {$[0.7377]$} \\
$p_{2}$ & 1.1876 & 1.4036 & 1.4214 & 1.5578 & $1.7960^{+, \mathrm{c}}$ & 0.8253 \\
& {$[0.2143]$} & {$[0.2607]$} & {$[0.2661]$} & {$[0.4040]$} & {$[0.3363]$} & {$[0.3374]$} \\
$p_{2} p_{1}$ & $-0.5018^{* *}$ & $-0.2847^{*}$ & -0.2752 & -0.2567 & 0.2743 & $-2.5830^{* * *}$ \\
& {$[0.2290]$} & {$[0.1667]$} & {$[0.1696]$} & {$[0.1717]$} & {$[0.2114]$} & {$[0.8946]$} \\
D_EC & & $0.6681^{*}$ & $0.6501^{*}$ & 0.6144 & & \\
& & {$[0.4014]$} & {$[0.3931]$} & {$[0.5269]$} & & \\
Event & & 0.1675 & 0.1787 & & \\
& & & {$[0.2581]$} & {$[0.3303]$} & & \\
DurPrev & & & 0.0234 & & \\
& & & & {$[0.0661]$} & & \\
Log- & -94.66 & -93.27 & -93.02 & -51.27 & -71.53 & -19.62 \\
likelihood & & & & & \\
SBIC & 200.31 & 201.2 & 204.37 & 124.19 & 153.37 & 43.41 \\
Spells & 39 & 39 & 39 & 22 & 31 & 8
\end{tabular}

*** statistically significat at $1 \%$; ** statistically sign ificant at $5 \%$; * statistically significant at $10 \%$.

Notes: Robust standard errors are reported in square brackets. $p_{2}-p_{1}$ is the estimated difference in the duration dependence parameters. The change point is located at duration equal to six years. ${ }^{+}$indicates that $p$ is significantly higher than 1 using a one-sided test with a $5 \%$ significance level; ${ }^{\mathrm{d}},{ }^{\mathrm{c}}$, and ${ }^{\mathrm{i}}$ indicate decreasing, constant and increasing positive duration dependence, respectively.

and evaluate the statistical significance of the difference between the two $\left(p_{2-} p_{1}\right)$.

The results are reported in table 3 . In column 1 we estimate a simple equation without covariates. In column 2 we control for differences in the average duration of fiscal consolidations between European and non-European countries. In columns 3 and 4 we account for the possibility that the duration of fiscal consolidation changes over time and depends on the duration of the previous spell.

Through we confirm that the duration of fiscal consolidation is typically longer for nonEuropean countries and there are no significant effects of the duration of previous spells on the duration of a given fiscal consolidation programme, the most interesting and remarkable 
results are the ones related to the duration dependence parameter. In fact, they strongly suggest that the duration dependence parameter is time-varying. In particular, despite the existence of positive duration dependence, the magnitude of the parameter is significantly lower when fiscal consolidation programmes are longer than six years: the coefficient associated with $p_{2}-p_{1}$ is negative and statistically significant. Positive duration dependence is still present in consolidations that last fewer than six years but, when their length is longer, duration dependence is not statistically significant; that is, the likelihood of ending is no longer dependent on their age. Indeed, while the parameter $p_{1}$ is statistically significant in all model specification, $p_{2}$ does not seem to exhibit statistical significance.

These results suggest that, when countries display chronic fiscal imbalances, the need of consolidation measures becomes a frequent characteristic. Putting it differently, countries will be eventually trapped in a vicious cycle of austerity and, as a consequence, the likelihood of a fiscal consolidation ending declines at a lower pace for programmes that are longer than six years. As a result, the evidence corroborates the idea that fiscal fatigue can be a threat to the implementation (and, consequently, the successfulness) of fiscal consolidation.

Finally, we consider separately the two subgroups of countries (ie, European and nonEuropean countries) in columns 5 and 6 . The empirical findings show that the presence of a change point is significant for non-European countries, but not for European countries. Even though the estimated difference in the duration dependence parameter $\left(p_{2}-p_{1}\right)$ is not statistically significant in this group of countries, the evidence still corroborates the existence of positive duration dependence for both consolidations that are shorter or longer than six years: the parameters $p_{1}$ and $p_{2}$ are positive (1.5217 and 1.7960, respectively) and statistically significant. For Non-European countries, the duration dependence parameter is larger in magnitude for consolidations that last fewer than six years (3.4083), and the results suggest that it is increasing. However, no evidence of duration dependence is found for longer fiscal consolidation programmes.

\section{Conclusion}

While some continuous-time and discrete-time duration models have successfully detected positive duration dependence in fiscal consolidations (Illera and Mulas-Granados, 2002), the existing works do not consider the possibility of breaks (or 'change points') in the duration dependence.

In this paper we argue that the likelihood of a fiscal consolidation ending changes as the programme becomes older. More specifically, we build on a novel database of fiscal consolidation episodes constructed by Devries et al (2011), and extend the basic Weibull duration model allowing for the presence of a change point in the duration dependence parameter. Using data for seventeen industrialized countries over the period 1978-2009, we confirm the presence of positive duration dependence in fiscal consolidations.

Interestingly, we uncover a change point in duration dependence. In particular, the magnitude of the duration dependence parameter decreases significantly when a fiscal consolidation programme is longer than six years. This implies that fiscal fatigue can undermine the efforts associated with fiscal adjustments and severely damage the successfulness of consolidation programmes. Additionally, while positive duration dependence is found for those consolidations that last fewer than six years, when duration is longer than this threshold, fiscal consolidations are not duration dependent. This is a remarkable new finding, as it shows that the likelihood of a fiscal consolidation ending increases at a constant rate with its age. However, when it is running for more than six years, the likelihood of its end no longer depends on the actual duration or age.

From a policy perspective, this result highlights that chronic fiscal imbalances can lead to a vicious austerity cycle, where consolidation measures may need to be implemented 
over longer time spans. This comes at the cost of high uncertainty about the timing of the consolidation ending and the additional contractionary packages that may be required to achieve a sound and sustainable fiscal stance.

Given the nature of the countries covered in this study, we also compare the characteristics of the duration of fiscal consolidation programmes between European and non-European countries. We find that fiscal consolidations tend to last longer in non-European countries than in European countries. The results also show the presence of a change point in the duration dependence parameter for non-European countries, but not for European countries. In addition, while positive duration dependence is always present in European countries, for non-European countries this happens only in fiscal consolidations that last fewer than six years.

This set of findings for European countries give rise to the role played by the commitment towards the Maastricht criteria for entry in the EMU and the compliance with the Stability and Growth Pact rules. It is also in line with the political support for a quick correction of budget deficits and the fear of crisis with roots on the unsustainable path of public debt.

Acknowledgments Castro and Sousa acknowledge that this work has been financed by Operational Programme for Competitiveness Factors - COMPETE and by National Funds through the FCT Portuguese Foundation for Science and Technology within the remit of the project "FCOMP-01-0124FEDER-037268 (PEst-C/EGE/UI3182/2013)".

\section{References}

Afonso A, Agnello L, D Furceri, 2010, "Fiscal policy responsiveness, persistence, and discretion" Public Choice $\mathbf{1 4 5}$ 503-530

Afonso A, Jalles J T, 2012, "Measuring the success of fiscal consolidations" Applied Financial Economics 22 1053-1061

Afonso A, Sousa R M, 2011, "What are the effects of fiscal policy on asset markets?" Economic Modelling 28 1871-1890

Afonso A, Sousa R M, 2012, "The macroeconomic effects of fiscal policy" Applied Economics 44 4439-4454

Agnello L, Castro V, Sousa R M, 2012, "How does fiscal policy react to wealth composition and asset prices?" Journal of Macroeconomics 34 874-890

Agnello L, Castro V, Sousa R M, 2013, "What determines the duration of a fiscal consolidation program?" Journal of International Money and Finance 37 113-134

Agnello L, Schuknecht L, 2011, "Booms and busts in housing markets: Determinants and implications" Journal of Housing Economics 20 171-190

Agnello L, Sousa R M, 2011, “Can fiscal stimulus boost economic recovery?” Revue Économique 62 1045-1066

Agnello L, Sousa RM (2014) How Does Fiscal Consolidation Impact on Income Inequality? Review of Income and Wealth 60(4) 702-726

Alesina A, Ardagna S, 2010, "Large changes in fiscal policy: taxes versus spending", in Tax Policy and the Economy (volums 24) Ed. J R Brown (The University of Chicago Press, Chicago, IL) pp. $35-68$

Alesina A, Perotti R, 1995, "Fiscal expansions and adjustments in OECD countries" Economic Policy 21 205-248

Blanchard O, 1990, "Comments on Giavazzi and Pagano", in NBER Macroecomics Annual Eds O Blanchard, S Fischer (MIT Press, Cambridge, MA) pp.111-116

Blanchard O, Perotti R, 2002, "An empirical characterization of the dynamic effects of changes in government spending and taxes on output" The Quarterly Journal of Economics 117 1329-1368

Castro V, 2010, "The duration of economic expansions and recessions: more than duration dependence" Journal of Macroeconomics 32 347-365

Castro V, 2011a, “Can central banks' monetary policy be described by a linear (augmented) Taylor rule or by a nonlinear rule?" Journal of Financial Stability 27 228-246 
Castro V, 2011b, "The impact of the European Union fiscal rules on economic growth" Journal of Macroeconomics 33 313-326

Castro V, 2013, "The duration of business cycle expansions and contractions: are there change-points in duration dependence?" Empirical Economics 44 511-544

Castro V, Sousa R M, 2012, "How do central banks react to wealth composition and asset prices" Economic Modelling 29 641-653

Devries P, Guajardo J, Leigh D, Pescatori A, 2011, “A new action based dataset of fiscal consolidation. International Monetary Fund, IMF Working Paper No. 128.

Feldstein, M, 1982, "Government deficits and aggregate demand" Journal of Monetary Economics $91-20$

Giavazzi F, Pagano M, 1990, "Can severe fiscal contractions be expansionary? Tales of two small European countries" NBER Macroeconomics Annual Eds O Blanchard, S Fischer (MIT Press, Cambridge, MA) pp 95-122

Granville B, Mallick S K, 2009, "Monetary and financial stability in the euro area: pro-cyclicality versus trade-off" Journal of International Financial Markets, Institutions and Money $19662-674$

Illera R M, Mulas-Granados C, 2002, "Duration of fiscal budgetary consolidations in the European Union", WP 18, European Economy Group

Kyriacou A P, Roca-Sagalés O, 2011, "Fiscal and political decentralization and government quality" Environment and Planning C: Government and Policy 29 204-223

Lancaster T, 1990 The Econometric Analysis of Transition Data (Cambridge University Press, Cambridge)

Mallick S K, Mohsin M, 2007, "On the effects of inflation shocks in a small open economy" Australian Economic Review 40 253-266

Mallick S K, Mohsin M, 2010, "On the real effects of inflation in open economies: theory and empirics" Empirical Economics 39 643-673

Mountford A, Uhlig H, 2009, "What are the effects of fiscal policy shocks?" Journal of Applied Econometrics 24 960-992

Mulas-Granados C, 2005, "Fiscal adjustments and the short-term trade-off between economic growth and equality" Hacienda Pública Española / Revista de Economia Pública 172 61-92

Nath S, Purohit B C, 1995, "Expenditure reassignment and fiscal decentralisation: an empirical study of state and local government in India" Environment and Planning C: Government and Policy 13 351-360

Rafiq M S, Mallick S K, 2008, "The effect of monetary policy on output in EMU3: a sign restriction approach" Journal of Macroeconomics 30 1756-1791

Sagbas I, Sen H, Kar M, 2005, "Fiscal decentralisation, the size of the public sector, and economic growth in Turkey" Environment and Planning C: Government and Policy, 23 3-19

Sepulveda C, Martinez-Vazquez J, 2011, "The consequences of fiscal decentralization on poverty and income inequality" Environment and Planning C: Government and Policy 29 321-343

Sichel D, 1991, "Business cycle duration dependence: a parametric approach" Review of Economics and Statistics 73 254-260

Sousa R M, 2010, "Housing wealth, financial wealth, money demand and policy rule: evidence from the euro area" The North American Journal of Economics and Finance 21 88-105

Tagkalakis A, 2011, "Fiscal adjustments and asset price changes" Journal of Macroeconomics $33206-223$

Zellner A, 1990, "Some properties of the durations of economic expansions and contractions" American Economist 34 20-27

Zuehlke T, 2003, "Business cycle duration dependence reconsidered" Journal of Business and Economic Statistics 21 564-569 